\title{
HOW THE CETERIS PARIBUS LAWS OF PHYSICS LIE
}

\author{
Geert Keil
}

After a brief survey of the literature on ceteris paribus clauses and ceteris paribus laws (1.), the problem of exceptions, which creates the need for cp laws, is discussed (2.). It emerges that the so-called skeptical view of laws of nature does not apply to laws of any kind whatever. Only some laws of physics are plagued with exceptions, not the laws (3.). Cp clauses promise a remedy, which has to be located among the further reactions to the skeptical view (4.). After inspecting various translations of the Latin term "ceteris paribus" (5.), the paper arrives at the conclusion that, on the most reasonable translation, there are no such things as $\mathrm{cp}$ laws, for reasons of logical form. Cp clauses have an indexical content, so that they need singular propositions as their habitat, not general ones. Cp clauses and the universal generalizations they are supposed to modify are not fit for each other (6.).

\section{Cp Clauses and Cp Laws: A Survey}

In the face of the "ragged character of the philosophical literature" on ceteris paribus clauses and ceteris paribus laws (Earman and Roberts, 1999, 461), I shall first give a brief survey of the field in order to background and locate my essential concerns. Let me distinguish five subtopics:

(i) Much of the recent literature on cp clauses and cp laws is motivated by a skeptical attitude regarding the laws of nature. Nancy Cartwright's influential view that "the laws of physics lie", in that they "do not tell what the objects in their domain do" (Cartwright, 1983, 55), has prompted a number of counter-reactions. One of these is the substitution of cp laws for strict laws, the idea being that universally quantified generalizations about empirical phenomena are plagued with exceptions, while cp clauses promise a remedy. Hedge a lawful statement with a cp clause, and it lies no longer. The unqualified law says something false, that is, it is subject to falsification by counterinstances. Then it gets 
hedged by a cp clause, and as a cp law it says something true. Or so it seems.

(ii) It has often been observed that strict laws are hardly to be found in biology, sociology, or history. Or, for that matter, in economics: Long before the philosophy of science took an interest in the topic, cp clauses were widely used and discussed in economics (more widely used than discussed, actually). ${ }^{1}$ It is true that " $[\mathrm{m}]$ uch work on the topic of provisos and ceteris paribus laws has been motivated by a concern to defend the special sciences" (Earman and Roberts, 1999, 472). Among those who feel the need to defend the scientific respectability of the special sciences against "physics chauvinism", many find comfort in the idea that physics might be no better off. They suspect that "science generally is riddled with ceteris paribus laws". ${ }^{2}$ Some authors, including Cartwright, go so far as to hold that "ceteris paribus clauses are endemic even in our best physics" (Kincaid, 1996, 64; see also Morreau, 1999, 163). Let's call this view the no-better-off view. The no-better-off view need not come down to the skeptical perspective. Many advocates of the special sciences regard the cp-hood of the laws of physics as harmless, and merely press for equal treatment. ${ }^{3}$ Others claim that this view is "based on a misguided egalitarianism about the sciences", while in fact it is "not 'ceteris paribus all the way down' - ceteris paribus stops at the level of fundamental physics" (Earman and Roberts, 1999, 439 and 472). Hence, the debated issue is how widespread the anomalous phenomena are for which cp clauses promise to be a cure.

(iii) In particular, it is questioned whether the rough generalizations of intentional psychology are capable of scientific refinement. There has been a recent debate on cp laws in the philosophy of mind, stimulated by two seminal papers of Jerry Fodor's and Stephen Schiffer's, ${ }^{4}$ and dealing with generalizations such as "If Tom wants a beer and believes there is one in the refrigerator, then he will go there to get it". The debate about the status of folk-psychological generalizations is older, of course. In Davidson's "anomalous monism", it's the "heteronomic" character

\footnotetext{
${ }^{1}$ For the history of the term "ceteris paribus" in economics, see Persky, 1990.

${ }^{2}$ Tye, 1992, 432. Likewise, Lakatos (Lakatos, 1978, 18) held that "ceteris paribus clauses are not exceptions, but the rule in science."

3 "Nobody in his senses would hold that the laws of mechanics were invalidated if an experiment designed to illustrate them were interrupted by an earthquake. Yet [economics is continually critized] on grounds hardly less slender." (Robbins, 1984, 97-98) From this perspective, it seems more appropriate to say that the special sciences are no worse off than physics. Earman, Glymour and Mitchell $(2002,277)$ call the no worse off view "the CP defence of the scientific status of the special sciences".

${ }^{4}$ Cf. Fodor, 1991; Schiffer, 1991; Klee, 1992; Warfield, 1993; Horgan and Tienson, 1996, 115-141; Guarini, 2000.
} 
of intentional generalizations that distinguishes intentional psychology from the rest of science. While "homonomic" laws are indefinitely refinable "by adding further provisos and conditions stated in the same general vocabulary as the original generalization", the heteronomic generalizations of intentional psychology can be improved "only by shifting to a different vocabulary" (Davidson, 1980a, 219). ${ }^{5}$ In recent times, the debate has shifted from the more general question how widespread unstrict, $\mathrm{cp}$ generalizations are in science, to the more specific question whether the roles that cp qualifications play, and the ways of spelling them out, differ from psychology to physics. For example, it is held that cp clauses in intentional generalizations (e.g., "if there are no overriding desires") account for "same-level exceptions" only, while in physical laws, provisos are supposed to exclude all possible interferences.

(iv) In the philosophy of science, a major issue is whether cp laws can be saved from the charge of vacuity. Hedging a universally quantified conditional by a clause such as "unless something interferes" is often said to render the law-statement trivial. A cp law had better not be equivalent with the logical truth that all $F$ s are $G$ s unless they are not. One way of providing non-trivial truth conditions for cp laws is the "completer account": The cp clause indicates that some additional condition $C$ exists that makes the antecedent of the law nomologically sufficient (Fodor, 1991, cf. Hausman, 1992, 133-139; Pietroski and Rey, 1995). If no such condition exists, the cp sentence in question is too vague so as to qualify as a cp law. Completer accounts go along with an interest in "distinguish[ing] legitimate from illegitimate uses of ineliminable ceteris paribus clauses" (Hausman, 1992, 133). It is often held that cp laws in the special sciences have completers in more basic sciences. Requiring, however, that some completer exist is one thing, while specifying it is quite another. As long as no independent specification of the completing clause is given, or a finite list of possible defeaters of the law, no real progress is made.

As the prospects for a breakthrough on this front are slight, some authors adopt a more radical strategy for saving cp laws from vacuity. Completer accounts, they say, leave the idea unchallenged that all genuine laws must be, or be amended until they are, universal generalizations. This idea is regarded as "fundamentally flawed" and "sharply at odds with standard scientific practice" (Woodward, 2000, 248 and 227). It is pointed out that "many a claim we believe to describe no reg-

\footnotetext{
${ }^{5}$ The conditions Davidson imposes on non-intentional laws are severe, and it has been objected that "if Davidson is correct, then there can be no purely physical laws either. ... Since there clearly are physical laws, Davidson cannot be correct" (Klee, 1992, 389).
} 
ularity at all, nomological or accidental, we nevertheless accept as a lawstatement" (Lange, 1993, 232). In a word, it seems that "we have many laws and few uniformities" (Cartwright, 1995b, 305). Consequently, these authors abandon the demand for exceptionlessness, and with that, regularity views of laws altogether. Alternative accounts include the views that laws of nature describe "Aristotelian natures", in the sense of "capacities" of natural substances (Cartwright, 1989 and Cartwright, 1992), physical forces (Lipton, 1999; Smith, 2002), or "causal powers" (Ellis, Chalmers), which are often regarded as dispositional properties of physical systems (Hüttemann, 1998), or as "defeasible causal tendencies" (Horgan and Tienson, 1996, Kincaid, 1996, 63-70).

(v) Still others dig deeper into the meaning of the term "ceteris paribus", trying to make quantificational sense of the clause, and trying to develop a semantics for cp claims. ${ }^{6}$ Is the clause a quantifier? ${ }^{7}$ If so, which variables does it bind? What is the logical form of cp laws? Or is the search for cp laws perhaps misguided, cp sentences not being lawlike? And how do we translate the Latin words "ceteris paribus" in the first place? Clearly, "other things being equal" is not the only option. In particular, the "ceteris absentibus"-reading introduced by Joseph deserves attention, according to which not the constancy, but the absence of other factors is required (Joseph, 1980). In the face of the different readings, it cannot be taken simply for granted that cp clauses are suited to modify lawful statements. Whether there are cp laws depends, among other things, on the logical form and the meaning of the cp clause.

\section{The Need for Cp Laws: The Problem of Exceptions}

The need for cp laws arises in view of the problem of exceptions, whereas the problem of exceptions arises only if laws are regularity claims. If laws, or lawful statements, ${ }^{8}$ are conceived of as universal generalizations about empirical phenomena, they are false. Even our best candidates are plagued with counterinstances. The problem of exceptions was known and discussed long before Cartwright entered the fray. Mill was well

\footnotetext{
${ }^{6}$ Kurtzman, 1973; Joseph, 1980; Johansson, 1980; Silverberg, 1996; Morreau, 1999; Schurz, 2001a.

7 "What is often apparently forgotten is that the phrase 'everything else' is analogous to a quantifier, which has the appearance of binding variables" (Kurtzman, 1973, 369).

${ }^{8}$ In the terminology I prefer, laws are statements, while the truth-makers for laws are empirical regularities or relations between universals, depending on the kind of law. Armstrong, Dretske, and Tooley use the term "laws" for the truth-makers, so that they need another word for the linguistic entities. "Law-statements" suggests itself. I stick to my nominalistic usage of "law", though, and call the worldly items "regularities".
} 
aware of it, and so were Russell, Hempel, Lakatos and many others. Michael Scriven once opened a paper with the remark: "The most interesting fact about laws of nature is that they are virtually all known to be in error" (Scriven, 1961, 91).

Exceptions, or counterinstances, are cases in which the antecedent of the law is fulfilled while the phenomenon mentioned in the consequent fails to occur. In the case of laws of succession, for example, it can always happen that just at the moment the first event has taken place and the second event is due to occur, something interferes which prevents it. As Peter Geach puts it: "For every alleged uniformity is defeasible by something's interfering and preventing the effect, to assert the uniformity as a fact is to commit oneself to a rash judgment that such interference never has taken place and never will" (Geach, 1973, 102). According to the classical empiricist view of laws as describing exceptionless regularities, each case where the effect is prevented counts as a falsification of the law. "By 'laws' I mean descriptions of what regularly happens", says Cartwright (Cartwright, 1999, 4). ${ }^{9}$ This view has much to recommend itself, for given that laws have the logical form of a universally quantified conditional, the characteristic of admitting no exceptions seems to be a built-in feature. ${ }^{10}$ Still, it is not strictly analytic that universal generalizations describe exceptionless regularities, since some laws correlate items to which the notions of regularity and exception have no application, more of which below.

According to the skeptical view, no such universally quantified conditional about empirical phenomena is true. As Cartwright puts it, even the laws of physics "do not tell what the objects in their domain do. If we try to think of them in this way, they are simply false" (Cartwright, 1983, 55). "Indeed not only are there no exceptionless laws, but in fact our best candidates are known to fail" (46). As the quotations show, there are two different ways to express this result. Either you may say that the laws of physics lie, i.e. that they make false assertions, or you say that the laws in question do not exist. The difference is merely verbal, depending on your definition of "law". If a law is defined as a true lawful statement, speaking of false or lying laws is a contradictio in adiecto, just as speaking of true laws is pleonastic. Seen in this way, the wording that there are no exceptionless laws of physics is preferable,

\footnotetext{
${ }^{9}$ Lewis even identifies laws with regularities, claiming that "whatever else a law may be, it is at least an exceptionless regularity" (Lewis, 1986, 45). Substitute "describes" for "is", and you obtain the view under discussion.

${ }^{10}$ Armstrong introduced "oaken laws" which admit of exceptions, in addition to "iron laws" and "steel laws", which don't. According to Lewis, he would have better called the oaken laws "rubber laws".
} 
the no-laws formulation being tantamount to the claim that there are no such things as false true statements. ${ }^{11}$

The core features of the classical empiricist view of laws are the following: Laws are true statements. Their logical form is that of a universally quantified conditional. They deal with empirical phenomena, not with the ideal objects of a model, nor with uninstantiated universals. They do not contain singular terms referring to particular objects, locations or times (the "Maxwell condition"). The conjunction of these conditions, most of which are indebted to logical empiricism, is sometimes called "the regularity account" of laws.

It has often been objected that all of these conditions can be met by accidental generalizations, as opposed to nomic ones. Some further condition seems to be needed, one that ensures the modal force of laws of nature, their necessity. The modal condition has been the source of much trouble. It has proven difficult to spell out exactly what the modal force consists of, and where it comes from. No analysis seemed reductive enough, for every proposal led into "the familiar unilluminating circle of analysis from a law's explanatory power, to its physical necessity, to its capacity for counterfactual support, to its lawlikeness, to its capacity to be inductively confirmed by its instances, to its explanatory power" (Lange, 1993, 243). For the present purpose, however, no modal reinforcement of empirical regularities is needed, since if Cartwright's version of the no-laws view is correct, there are no exceptionless regularities in the first place, regardless of their modal status. I mention this only because there is a second variety of skepticism about laws of nature, which is directed exclusively at their modal status. Bas van Fraassen "frankly advocate[s] the philosophical view that there are no laws of nature" (van Fraassen, 1989, 183), but his no-laws view, just like that of Ron Giere's, is in sharp contrast with Cartwright's no-regularities view, as his rhetorical question reveals: "If we say that the regularities are all there is, shall we be so badly off?" (ibid.). This kind of skepticism is nicely illustrated by van Fraassen's story of the omnipotent spaceship commander who travels through our galaxy and types the command "delete all laws" into his console, only to witness no changes whatsoever (cf. 1989, 90 f.). Van Fraassen envisages a world in which the deletion of all laws makes no difference to the course of events. What gets deleted are not the regularities, but only modal pseudo-facts about them.

\footnotetext{
${ }^{11}$ In order to avoid the harsh conclusion that there are no laws, Swartz distinguishes between "physical laws" and "scientific laws", and he makes it clear that "Scriven's point is about the pronouncements of science, about what scientists call 'laws'" (Swartz, 1985, 4).
} 
In discussing the problem of exceptions, the modal status of the regularities can be neglected. So I shall stick to the regularity view, according to which any genuine law expresses "at least an absolutely unbroken regularity". This view leaves room for modal reinforcement, but is at odds with the view of laws as relations between universals and with the dispositional view. My reason for abiding with the regularity view is not, as some might suspect, that I like flogging a dead horse. The first reason is the intimate connection between laws and causality, while not just any law has a causal interpretation. The "principle of the nomological character of causality", as Davidson has called it, presupposes laws of a special kind. Secondly, and more important, not just any kind of laws calls for provisos. As mentioned above, the need for cp laws arises in the face of the problem of exceptions, and the problem of exceptions arises only if laws are claims of regularity. The dispositional account, by contrast, says that laws of nature describe dispositional properties of natural substances or of physical systems. According to this view, laws are "not about what things do but what it is in their nature to do" (Cartwright, 1992, 48), or "about the powers they possess" (Cartwright, 1983, 61). Laws do not state what de facto always happens, rather they say how a substance, given its nature, would behave under certain circumstances, e.g. in isolation. This conception of laws, however, is already a reaction to the intractability of the problem of exceptions. Statements about dispositions, powers, tendencies or natures, need no hedging, since such statements remain true even if the manifestation of the disposition is prevented by some external influence. This is why disposition talk is so useful: The possession of a dispositional property need not manifest itself in strict empirical regularities.

Nor are cp clauses needed if laws are relations between universals. Consider the much discussed case of interaction between gravitational force and electrical charge. "It is not true", says Cartwright, "that for any two bodies the force between them is given by the law of gravitation. Some bodies are charged bodies, and the force between them is not $G m m^{\prime} / r^{2}$ " (Cartwright, 1983, 57). When forces interact, the law of gravitation does not give us the resulting force, and for that reason it does not tell the truth about how bodies in its domain always behave. But, no one should have expected this in the first place. Newton's law makes an assertion about the ratio between distance, masses and gravitational force, and this assertion is not falsified by charged bodies. The gravitational force between two charged bodies is still $\mathrm{Gmm}^{\prime} / \mathrm{r}^{2}$, even if gravitation is not the only force present.

According to the concepion of laws as relations between universals, "laws eschew reference to the things that have length, charge, capacity 
[etc.] in order to talk about these quantities themselves and to describe their relationship to each other" (Dretske, 1977, 262). As long as these quantities are not measured quantities, but properties, i.e. universals, the relations between them are not affected by intervening factors or additional forces. Such laws simply don't make any claim about instantiations in our messy world. Assertions about relations between universals are not refuted by counterexamples to assertions about empirical regularities. ${ }^{12}$ We need not enter, however, into a discussion regarding what the laws of physics essentially are. It will suffice, and seems more appropriate, to distinguish between different kinds of laws, as I shall do below. It is an exaggeration to maintain that the laws of physics lie. The claim under discussion is that some laws of physics are exception-ridden, and call for provisos.

\section{How Some Laws of Physics Lie}

Can the advocates of the regularity account provide any instances? Yes, some lawful statements about the physical world seem to describe what always de facto happens:

1 "Whenever a spark passes through a mixture of hydrogen and oxygen gas, the gases disappear and water is formed." (Nagel, 1961, 74)

2 "[S]tones thrown into water produce a series of expanding concentric ripples." (Nagel, 1961, 76)

3 "Whenever the temperature of a metal bar of length $L_{0}$ changes by $\Delta T$, the bar's length changes by $\Delta L=k \times L_{0} \times \Delta T$, where $k$ is a constant characteristic of that metal." (Lange, 1993, 233)

These laws are cited by Nagel and Lange as examples of causal laws. Admittedly they are generalizations of the right kind, being laws of succession. They say something about which events always follow one

\footnotetext{
${ }^{12}$ Armstrong rejects uninstantiated universals, though. He claims that the relation of necessitation between $F$-ness and $G$-ness "entails the corresponding Humean or cosmic uniformity: $(x)(F x \rightarrow G x)$ ", so that "[a]ll genuine laws are instantiated laws" (Armstrong, 1983, 85 and 172). The entailment thesis is clearly wrong. In general, no relation between universals entails empirical facts about instances. Armstrong succumbs to what van Fraassen has described as "the inference problem", which can be expressed in the question: "What information does the statement that one property necessitates another give us about what happens and what things are like?" The answer is, from a logical point of view, "none whatsoever". There is an inferential gap. "Nothing less than a bare postulate will do, for there is no further connection between relations among universals and relations among their instances" (van Fraassen, 1989, 96 and 107).
} 
another. Making assertions about the series of events, they have a direct causal interpretation, for causality is a relation between events. The view that only events can be causes has not gone unchallenged, but I shall assume it here without argument. ${ }^{13}$

The nomological view of causality says that every singular causal statement implies a strict law that covers the case. This view is held by Hume, Kant, Mill, Hempel, Popper, Stegmüller, Davidson and Lewis, among others. Davidson has called the view, somewhat clumsily, "the principle of the nomological character of causality" (Davidson, 1980a), or, more recently and less clumsily, the "cause-law thesis" (Davidson, 1995). In his version, the cause-law thesis says that if two events " $c$ and $e$ are related as cause and effect, there exist descriptions of $c$ and $e$ that instantiate a strict law" (Davidson, 1993, 312-313). ${ }^{14}$ We need not know this strict law nor the descriptions, but they must perforce exist. According to the cause-law thesis, not just any connection between laws and causation will suffice. A causal law must exist that actually covers the case, causal laws being "laws that do subsume cause-effect pairs" (Cummins, 1983, 5).

The nature of causal laws depends on what kind of entities are admissible as causal relata. If it is taken for granted that only events can be causally related, then only laws about the succession of events can be causal laws, i.e. laws that say "Whenever an event of the type $c$ occurs, it is followed by an event of the type $e$ ". Such laws make a claim about what happens. Not every physical law does so. For example, the law of the pendulum says something about the ratio of the length of a pendulum to its frequency of swinging. Boyle's Law says something about the ratio between the pressure, temperature and volume of an ideal gas. These laws are laws of coexistence, not laws of succession. They say something about simultaneous, or rather timeless, relations between properties, or between physical quantities. ${ }^{15}$ The distinction between laws of succession and laws of coexistence goes back to Mill. "The phenomena of nature", Mill states, "exist in two distinct

\footnotetext{
${ }^{13}$ There are other candidates, for example Aristotelian substances (things and persons, in particular), facts, states, point events, dispositions, and tropes. All these entities have been promoted to causes and effects in various theories of causation. In my opinion, there are powerful arguments against all these candidates, but I cannot rehearse them here.

${ }^{14} \mathrm{Or}$, more precisely: " $A$ caused $B$ ' is true if and only if there are descriptions of $A$ and $B$ such that the sentence obtained by putting these descriptions for ' $A$ ' and ' $B$ ' in ' $A$ caused $B$ ' follows from a true causal law." (Davidson, 1980b, 16)

${ }^{15}$ More precisely, Boyle's law is "one of a large class of laws ... that are called 'constitutive equations'..., which describe the behavior of specific materials". Such laws have been regarded as "definitions of materials" (Smith, 2002, 255). Cummins calls such laws "nomic attributions" (see below).
} 
relations to one another; that of simultaneity, and that of succession", and accordingly they obey two kinds of laws (Mill, 1973, 323 [III, v, §1]). Thereupon, Mill makes a crucially important remark: "[U]nless there [are] laws of succession in our premises, there could be no truths of succession in our conclusions" (ibid., 325). Mill correctly states that no truth about what actually happens can be derived from truths about simultaneous relations alone.

This observation contradicts the standard account of the relationship between both kinds of truths. Laws of coexistence are typically expressed in the form of equations. Now it is often held that if such an equation contains a reference to time, it allows the derivation of an appropriate empirical truth, in the following way: "A differential equation containing time-derivatives, of whatever order, can in principle be integrated with respect to time, and will then tell us what later states of the system will regularly follow such-and-such earlier ones. [...] If functional laws could not thus be integrated with respect to time to yield actual changes, functional laws would be of little interest or use" (Mackie, 1980, $147 \mathrm{f}$.). ${ }^{16}$

This view, though mathematically compelling, is metaphysically mistaken. Integrating differential equations will never yield empirical truths about what de facto always happens. The only values that can be derived are those of instantaneous states of physical systems (sometimes called "point events"). Point events, however, must not be mistaken for empirical events of the kind mentioned in causal laws. The notion of an instantaneous state "is only a mathematical abstraction, which derives its entire meaning from the concept of a time interval" (Steiner, 1986, 251). Instantaneous states are inadmissible as causal relata, for causes and effects are changes, and every change takes time. Causation, on this picture, is a relation between two changes, not one between two temporally non-extended cross-sections of a physical process. ${ }^{17}$

The cause-law thesis assumes genuine laws of succession, i.e., laws that have cause-effect pairs as instances. Laws of coexistence, in con-

\footnotetext{
${ }^{16}$ Russell puts it like this: "[L]aws, as they occur in classical physics, are concerned with tendencies at an instant. What actually happens is to be inferred by taking the vector sum of all the tendencies at an instant, and then integrating to find out the result" (Russell, 1948, 316). Sheldon Smith has recently complained that many authors "fail to properly analyze the logic of the derivation of the differential equation". In particular, he emphasizes the difference between the solution of the differential equation, which describes the actual temporal behavior, and the law(s) used to derive the equation. Smith calls to mind the "Euler recipe" for deriving the equations of motion in point particle mechanics (Smith, 2002, 243 f.).

${ }^{17}$ The two changes view of the causal relation has been advocated by Ducasse (Ducasse, 1968). Incidentally, I use "event" and "change" interchangeably, just like Davidson does (see Davidson, 1995, 272). For a more detailed discussion of point events, differential equations and causal laws, see Keil, 2000, 249-260.
} 
trast, are tailor-made to the view of laws as relations between universals. The no-laws view which $I$ endorse is simply that no universally quantified conditional of the former kind is true. All laws of succession asserting that whenever an event of the type $c$ occurs, it is followed by an event of the type $e$ - are falsified by counterexamples, or, if you like, by exceptions. In fact, the so-called "skepticism about laws" is an unfortunate turn of phrase. One does not require a distinctly skeptical attitude in order to notice that laws of succession which state empirical regularities are plagued with exceptions. It is a hardly disputable empirical finding that series of events do not exhibit exceptionless regularities. Cartwright's claim that the laws of physics lie is often discussed in too general terms, i.e. without paying attention to the kind of laws the skeptical view applies to. If properly delimited, the skeptical view should not be a contentious one at all. Cartwright draws an unclear distinction between "fundamental" laws and "phenomenological" laws. The all-important distinction, however, is of that between laws which state what actually happens and those which do not. In some places, Cartwright parallels both distinctions, and sometimes she says that "applying" the fundamental laws yields descriptions of the happenings: "If the fundamental laws are true, they should give a correct account of what happens when they are applied in specific circumstances. But they do not." (Cartwright, 1983, 13).

Consider Newton's law of gravitation. It does not say, nor does it imply, that whenever a body falls to the ground from a height of one meter, it will hit the ground at such-and-such a speed. Actually, most bodies will be slower, and some will never touch the ground, such as bread-crumbs which are caught by greedy seagulls. I have witnessed such cases. Did those seagulls falsify the law of gravitation? No. But the reason for their being innocuous is not that some kinds of disturbances could be neglected when testing succession laws. The reason is that Newton's law does nor purport to state which events always follow one another in the first place. It says something about how the gravitational force between two bodies depends on their masses and their distance. It does not say anything about the total force between actual bodies, nor does it mention other factors or disturbances. It asserts the existence of a gravitational force, and this assertion is not falsified by seagulls or other mischiefmakers.

The insight that many laws say nothing about the temporal behavior of physical systems has been used to counter Cartwright's bold claim that the laws of physics lie. The law of universal gravitation, so the counter-objection goes, "cannot misrepresent the motion of the body, because it says nothing specific about such temporal behavior" (Earman, 
Roberts and Smith, 2002, 286; see also Smith, 2002, 245). Smith goes so far as to claim that "once one arrives at temporal claims within physics ..., one is generally trafficking in something other than a law" (Smith, 2002, 247). ${ }^{18}$ But, recognising that some fundamental laws of physics say nothing about temporal successions is not easily distinguished from claiming that they do not describe the empirical facts, as Cartwright does. The only difference is that Earman, Roberts and Smith insist that fundamental laws do not even purport to describe empirical regularities. But this is more a matter of emphasis. The dispute seems to boil down to the question which expectations it is wise to entertain, and which amount of surprise is in order. Apart from that, I would maintain that Earman, Roberts and Smith keep to an unbalanced diet: The fact that force laws, such as the law of gravitation, do not purport to describe empirical regularities does not show that no laws whatsoever do.

It has been noticed before that "[s]cientists do not try to describe natural events in terms of what always happens" (Geach, 1973, 102). This observation has prompted different reactions, though. Geach draws an Aristotelian moral from the failure of physics to provide strict laws of succession. Nature does harbour invariances, yet her stable and general traits are not to be found in strict empirical regularities but in the essential properties of natural substances. Sometimes these properties do manifest themselves in empirical regularities (especially in the laboratory), but sometimes not, due to some interference or to abnormal conditions. Hydro-chloric acid dissolves zinc - this is a general truth about the natures of hydro-chloric acid and of zinc. Using Cummins' terminology, we may call these general truths nomic attributions, i.e. "lawlike statements to the effect that all X's have a certain property P" (Cummins, 1983, 7). We may further say, as Horgan and Tienson do, that statements like "Hydro-chloric acid dissolves zinc" report "defeasible causal tendencies", and as such, are undoubtedly general truths with empirical content. "Since there are systematic patterns of defeasible causal tendencies," Horgan and Tienson maintain, "there should be soft laws reporting such tendencies" (Horgan and Tienson, 1996, 121). ${ }^{19}$

\footnotetext{
${ }^{18}$ See also Earman, Roberts and Smith, who hold that "differential equations with time as the independent variable describing the evolution in the physical magnitudes of a given system" are not laws at all, but applications of a theory to a specific case. "Differential equations of evolution type" cannot count as laws because they are derived using non-nomic boundary conditions of specific cases (Earman, Roberts and Smith, 2002, 298 and 286).

${ }^{19}$ Lipton even submits that describing dispositions is precisely the job of ceteris paribus laws. In his view, cp laws "describe dispositions or forces that are stably present whether or not all things are equal" (Lipton, 1999, 155). The moral he draws from his dispositional account is that cp laws "point to the simpler reality that sometimes underlies the complexity of the phenomena" (ibid., 163).
} 
The fact that these systematic patterns fall short of strict regularities does not make them any less empirical. I take it for granted that Horgan and Tienson have occurrent patterns in mind. Otherwise, it would be hard to see what exactly "patterns of tendencies" should be, ontologically speaking. Tendencies qua dispositional properties can hardly be said to build patterns unless they get instantiated. But as to the "soft laws" reporting the patterns of manifestations, disturbances stemming from other tendencies do not need to be ruled out. ${ }^{20}$

Working scientists are much more Aristotelian in spirit than empiricist philosophers of science often tried to make us believe. The return of Aristotelian natures, essential properties and dispositions is by no means a relapse into prescientific scholasticism, for "many of the most pressing and puzzling scientific questions are questions about properties, not about changes" (Cummins, 1983, 15). Why did the litmus tincture turn red? If the triggering cause of the event is sought for, the answer would be: because acid was poured into the test-tube. Citing the causing event, however, will fail to enlighten anyone who has witnessed the experiment. In science, we seldom ask for the triggering cause. At least in observable cases, the cause is obvious enough. More often we want to know something about the dispositional properties of the substances involved, trying to find out by what exactly the effect produced was $F$, rather than $G$.

Physical science is doing quite well without strict laws of succession. The fundamental laws that physicists are so proud of are different in character. The only ones who are left empty-handed are the philosophical champions of the cause-law thesis. The good news is that only some laws of physics lie; the bad news is that these are exactly those laws which Kant, Mill, Hempel, Stegmüller, Davidson and Lewis invoke, and which they need, claiming that whenever two events are related as cause and effect, there exists a strict empirical law that covers the case. Laws about simultaneous, or rather timeless, relations between universals, may be strictly true, but have no causal interpretation. With generalizations about tendencies or dispositions, it's more complicated, but it should

\footnotetext{
${ }^{20}$ As Horgan and Tienson say, "it is no part of the law's role to delimit all ways that a causal tendency belonging to this pattern might get defeated when interacting with other defeasible causal tendencies" (ibid., 122). Hempel makes a similar point: "A scientific theory propounds an account of certain kinds of empirical phenomena, but it does not pronounce on what other kinds there are. The theory of gravitation neither asserts nor denies the existence of nongravitational forces, and it offers no means of characterizing or distinguishing them." (Hempel, 1988, 30) Earman and Roberts suggest that the provisos Hempel speaks of "are not provisos proper but are simply conditions of application of a theory" (Earman and Roberts, 1999, 444).
} 
have become clear that they do not support the Davidsonian cause-law thesis either. ${ }^{21}$

The scientific significance of strict laws of succession has always been overestimated by D-N theorists. And this is why the achievements of physics are not belittled by the verdict that some laws of physics lie. This is also why I am not intimidated by the warning that "if we demand that all genuine laws must be exceptionless, it follows that we know very few laws" (Woodward, 2000, 228). I do not demand that all laws must be exceptionless, only that empirical laws of succession be. The notion of exception has no direct application to laws about properties, exceptions being counterinstances. Remember that assertions about relations between universals cannot be refuted by cases which falsify succession laws.

I distinguished succession laws from coexistence laws, following Mill. I am well aware that the latter category is a very mixed bag, including force laws, conservation principles, functional laws, nomic attributions, composition laws and some others. A comprehensive classification of physical laws is still to come, but for the present purpose, my rough division will do.

\section{Yes, But Reactions to the Skeptical View}

I said above that the no-laws view, properly delimited, should go undisputed, and that it is an empirical finding rather than a philosophical claim. This was of course an exaggeration. The view in question is not undisputed. The philosophy of science is bristling with counterreactions, with "Yes, but" replies. The skeptical view is easily put forward, and often enough the friends of the laws even buy into it, calling it a superficial insight, or one that rattles an unlocked door. The exciting job is to parry all the yes, but reactions that will inevitably follow. I have tried to do this in some detail elsewhere. ${ }^{22}$ Let me just list the

\footnotetext{
${ }^{21}$ Some philosophers claim that these are causal laws, in that "they cite real causes at work", since tendencies "are partial causes" (Kincaid, 1996, 65). Obviously opinions are divided concerning what causal laws are about. I reserve the term "cause-law thesis" for the kind of laws described above: universally quantified conditionals which subsume cause-effect pairs, in the straightforward way. In this view, a cause is a causing event. General traits, factors, forces, or tendencies may be referred to in causal explanations, but they cannot cause anything. There are no such things as "general causes". There are general causal sentences, like "Smoking causes cancer", but these are deceptive. This alleged generalization describes a disposition, or a tendency, or perhaps a statistical fact, but it is not a universal truth concerning events. It does not allow deduction of singular causal truths. It is not the kind of law that the Davidsonian cause-law requires, and which can be used in D-N explanations of the occurrence of events.

${ }^{22}$ Cf. Keil, 2000, 182-260.
} 
most common replies the friends of the laws have in their quiver, before discussing the appeal to cp clauses.

Some say that empirical laws are at least approximately true. Others say that laws are idealizations: they don't deal with empirical objects, but with the ideal objects in a model, and they are entirely true of those objects. This view is reminiscent of the Platonist-Galilean view that the Book of Nature is written in mathematicalese. Still others say that the empirical laws which are true to the facts are statistical laws which cannot be falsified, strictly speaking, by single instances. Some philosophers of science promote instrumentalism. Laws, they say, are useful instruments in the scientific enterprise, but they need not be true to serve that purpose. Cartwright sometimes flirts with this line of thought. "We are lucky that we can organize phenomena at all", she says. "There is no reason to think that the principles that best organize will be true, nor that the principles that are true will organize much" (Cartwright, 1983, 53). Still another remedy is the dispositional view of laws mentioned above. And last but not least, it is said that empirical laws are false if taken at face value without qualification, but true if qualified with a cp clause.

We may try to systematize these reactions to the skeptical view by relating them to the various features of lawfulness which the philosophy of science has come up with. Taking for granted the classical empiricist view, and focusing on the three conditions (i) that laws have to be true, (ii) that they deal with empirical phenomena, and (iii) that they are strict - i.e. admit of no exceptions -, we can say that most of the proposals just enumerated amount to dropping one of these conditions in favour of the others. For example, the instrumentalist says: Laws are strict and deal with empirical phenomena, but they need not be true. The Platonic idealist says: Laws are true and strict, but not true of the empirical world. The champion of cp laws says: Laws are true and about the empirical world, but they are not strict.

Calling counterinstances to empirical laws "exceptions" is tendentious. It's a kind of euphemism. One could as well speak of falsifying instances and leave it at that. While no special skeptical attitude is needed to notice the problem of exceptions, a widespread charitable attitude explains why we do not go around decrying all laws as false, even in the face of counterinstances. ${ }^{23}$ Some counterinstances, the friends of the laws hope, can be explained, or explained away. Such cases are

\footnotetext{
23 "We do not go around decrying all physical laws as false (although they are not exactly true) because they serve the crucial explanatory role of singling out a preferred value from which, it is alleged, all deviations can be explained." (Scriven, 1959, 467)
} 
reckoned as pseudo-falsifications. ${ }^{24}$ Prima facie, they falsify the law in question, but for some reason or other we think that we can eventually cope with them. If we expect to cope with the counterinstances in a certain way, we call them "exceptions", which are due to "disturbing factors". If we expect to cope with them in a different way, we call them "inaccuracies". Pietroski and Rey have introduced a very useful distinction between catastrophic and noncatastrophic interferences (Pietroski and Rey, 1995, 94-97). The latter are distinguished by the fact that the law interfered with yields at least approximately the correct result. The inaccuracy of the prediction is due to an imperfect realization of the conditions stated in or presupposed by the law. The mercury in the thermometer is impure, the vacuum is incomplete, friction occurs etc. But a vacuum can be increased gradually, and if the measured result correspondingly approaches the predicted result, the experimenter feels entitled to close the remaining gap by Galilean idealization. Idealizations, it is said, "involve exaggerating some actual property toward some limit" (Hausman, 1992, 131).

With the behaviour of greedy seagulls, it's different. Such catastrophic interferences are not amenable to systematic consideration, and they can prevent that something even remotely similar to the predicted effect occurs. I wish to suggest that it are just these catastrophic interferences which create the need for cp clauses, while inaccuracies and impurities call for idealizations and approximations. If ideal conditions are insufficiently realized, "the problem is not in saying precisely what is involved in the idealization but in relating it to the real world which is not ideal" (Earman and Roberts, 1999, 457). With catastrophic interferences, it's different. They call for an unspecified proviso, for there is no reason to suppose that a complete list of such incidents is available for any empirical law. Cp clauses proper are needed when the cetera are not known.

Since real world situations are susceptible to both catastrophic and noncatastrophic interferences, both must be made provision for. Even if, in a given law, all the impurities in the explicitly stated conditions are accommodated by appropriate idealizations, there is still a proviso needed for catastrophic interferences. Some provisos are even dualpurpose tools. Unspecified ceteris absentibus clauses (of which more

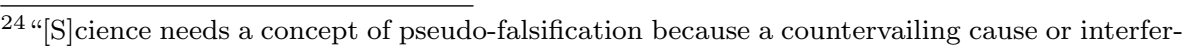
ing agent may be at work generating the 'counterinstance'. It is only under closed conditions ... that a theory can be given a fair test or that a crucial experiment ... becomes possible" (Bhaskar, 1978, 161). "We call the laws by the honorific term 'idealization' rather than by the pejorative term 'falsehood' because ... we can easily perform thought-experiments in which the disturbing factors ... are removed." (Joseph, 1980, 774)
} 
below) are strong enough to rule out both kinds of interference with a single blow.

Let us now look into the question what exactly cp clauses do with the statements they qualify. Which abuses they are supposed to redress is clear enough. We are talking about provisos "without which a putative law would not be a law ... for the fundamental reason that it would be false unless qualified" (Earman and Roberts, 1999, 444). The suggestion is that cp clauses are capable of turning false generalizations into true ones.

Cartwright sums up her early views as follows: "[T]he fundamental laws of physics do not describe true facts about reality. Rendered as descriptions of facts, they are false; amended to be true, they lose their fundamental, explanatory force" (Cartwright, 1983, 54). Leaving aside the issue of explanatory force for the moment, the question is how a false generalization can be "amended to be true". It could be done by modifying the law so that it no longer applies to the irregular case. In the face of a counterinstance, we can identify the interfering factor and use this information to improve the law. We simply complete the antecedent with a clause that excludes that very factor; for example, "no friction occurs", or "no electromagnetic forces are present". ${ }^{25}$ Of course, such an ad hoc amendment will restrict the range of application of the law to cases where the factor in question really is absent. In some cases, we can do even better. Friction, for example, is sufficiently understood as to admit of systematic consideration in a super law, that is, in a combination of two laws by means of vector addition. Physics textbooks record the law of falling bodies with friction in a medium as a familiar example.

Amending a law to be true in either of the two ways has a price, though. As Cartwright observes, "a law that holds only in restricted circumstances can explain only in those circumstances" (Cartwright, 1983, 155). It goes without saying that disturbing factors cannot be removed by simply postulating that they are absent. Disturbed cases may still occur that will remain unexplained by the specified law. Not only is there no reason to suppose that a complete list of possible catastrophic interferences will be available, it is not even advisable to make provisions for every conceivable incident. If we keep making ad hoc amendments to rule out various kinds of disturbances, we keep narrowing down the

\footnotetext{
${ }^{25}$ Often, such completions are framed as "boundary conditions", in order not to burden the law itself, or the scientific theory it belongs to, with too many provisos. Boundary conditions are mostly conceived as restricting the range of application of the law, which has to be done before its truth-value can be judged.
} 
range of application of the law. Carried to extremes, we will end up with a true conditional with a hypercomplex antecedent that is fulfilled only once in the lifetime of the universe. Cartwright draws just this moral: "If I am right, a law that actually covered any specific case, without much change or correction, would be so specific that it would not be likely to work elsewhere" (Cartwright, 1983, 112). ${ }^{26}$ There is, in other words, "a trade-off between truth and explanatory power" (ibid., 59). In the world we inhabit, you cannot have both at once - statements which have a wide range of application and which tell the truth about what happens in every specific case. "The truth doesn't explain much", Cartwright summarizes. That this tension exists is no a priori insight. If the world were not such a messy place, both ends could be achieved with statements of the same kind. It is obvious that the availability of laws which are both true and explanatory was an assumption implicit in the D-N-model of scientific explanation. This assumption was mistaken, and this fact contributed to the decline of the D-N model.

Catastrophic interferences can destroy laboratories, but they do not worry theoretical scientists excessively. Shielding an experimental set-up from catastrophic disturbances is an engineering task rather than a matter of hedging the relevant law(s) with countless ad hoc clauses. In fact, "physicists do not add the required clauses; they leave the expression of the law as it is" (Smith, 2002, 240).

And worse yet, even if a complete list of possible catastrophic interferences were available, this list could arguably not be used to turn a false nomic generalization into a true one. For if we had such a list, and used it to complete the antecedent of the law, we would still "not have a strict law, because the completed antecedent would yield a universal conditional that is true but not a law, only an accidental generalization" (Lipton, 1999, 160) The completed antecedent would specify the cases where the interfering actors are absent, but since it is generally a contingent matter when and where interference occurs, such "a strict antecedent purely in occurrent terms would fail to be lawlike", according to Lipton (ibid., 165). ${ }^{27}$ I'm not quite sure whether this claim of

\footnotetext{
${ }^{26}$ This consequence had been discussed some decades before in the controversy between Hempel and Dray about laws in history. Scriven had pointed out then that a certain historical 'law' with a couple of ad hoc amendments "has become more trivial, i.e., less general, in the course of becoming more nearly correct and now appears quite possibly to have only one instance" (Scriven, 1959, 455).

${ }^{27}$ Similarly, Earman, Roberts and Smith observe that in the case of interaction between gravitation and electrical charge, hedging the law of gravitation with the clause "no other forces present" would deprive the resulting statement of its lawful character, since the proviso would bring in a "non-nomic assumption" (Earman, Roberts and Smith, 2002, 287; cf. Smith, 2002, 247 f.).
} 
Lipton's is correct, because the demand that the law be nomic does not apply to its antecedent clause, strictly speaking. Given that laws are conditionals, it seems that the antecedent does not maintain that none of the interferences is in play, contrary to what Lipton suggests (ibid., 160). Rather the completed law says that if all these specified factors are absent, such-and-such will happen. As far as I can see, such a conditional could still be lawlike, provided it does not contain singular terms referring to particular objects, locations or times. So I think that the better way to frame this kind of objection is the one taken above: We would end up with a law with a hypercomplex antecedent which applies only once, viz. to the particular situation for which it was tailored. Formally, the sentence could be lawlike, but it would fail to be a covering law. But, all this holds only if we had a complete list of what could possibly disturb a real world situation, and there is no reason to suppose that knowledge of such a list is within our cognitive powers.

\section{How to Translate "Ceteris Paribus"}

Not just any qualification which aims to restore the truth of a law qualifies as a cp clause. It is high time to clarify the Latin phrase "ceteris paribus", before we can hope to determine which role cp clauses can play in laws. There is little reason to switch, midst of the formulation of a law, to Latin and return to English after two words. So, how to translate "ceteris paribus"? As far as I can see, there are at least six standard readings, only some of which can be judged translations:

1 other things being equal

2 all other things being equal

3 under normal conditions

4 under ideal, or optimal, conditions

5 provided nothing interferes

6 all other forces being absent (ceteris absentibus)

The difference between clause (1) and clause (2) is that the first leaves it open how many of the other things are supposed to be equal. Clause (2) invites the comment that all other things are never equal. It is very unlikely that two events ever occur under exactly the same circumstances - that is, under circumstances of exactly the same kind, apart from spatiotemporal position, of course. As far as we know, history does not repeat itself. (The issue of eternal recurrence I set aside, for in this 
case, the very notions of repetition, and of numerical identity, become doubtful.) It was one of Russell's arguments against causal laws that the more precisely the antecedent of a causal law becomes specified, the less likely it is that such a case will ever recur. ${ }^{28}$ All circumstances never being equal, hedging a law by clause (2) is cognate with the idealization strategy. Such a "law" had better be expressed in the subjunctive mood: Such-and-such would happen if, per impossibile, all other things were equal. Lipton has dubbed this problem "the problem of instantiation. Many cp laws appear to have no instances at all, because things are never 'equal' in the requisite respect" (Lipton, 1999, 157).

If, on the other hand, the proviso fixes less than all other things, as in clause (1), the natural question is: which ones? The reply is that we do not know. If we did know, we could use this knowledge to specify the antecedent of the law, as described above. We would simply rule out the circumstances in which the effect does not materialize, or we would combine all known factors or forces to formulate a super law. Such a specification, however, should not count as a cp qualification. We should reserve the term "cp clause" for unspecified provisos, in order to mark the difference between both manoeuvers. It has often been observed that cp clauses "are needed in science precisely when it is not clear what the 'other things' are" (Pietroski and Rey, 1995, 87), that is, when "no definite claim is in the offing" (Earman and Roberts, 1999, 452).

Cartwright calls a law that holds only in specified circumstances a cp law as well (Cartwright, 1983, 47). Doing this, she confounds both devices, and covers up the reasons why an unspecified proviso is still needed after we have done our best to improve the law by specifying the antecedent. The first reason is that the need to make an indefinite number of specifications makes it impossible to spell out the antecedent, so that the law would be "incapable of being written down explicitly" (Giere, 1988, 40). ${ }^{29}$ A second reason is that making provisions for a certain disturbing factor will not even do for that very factor. Consider again the law of thermal expansion as applied to metal bars: "Whenever the temperature of a metal bar changes by $\Delta T$, the bar's length changes by $\Delta L$ ". This unqualified generalization does not seem to be true. We

\footnotetext{
28 "As soon as the antecedents have been given sufficiently fully to enable the consequent to be calculated with some exactitude, the antecedents have become so complicated that it is very unlikely they will ever recur" (Russell, 1986, 188).

${ }^{29}$ See also (Lange, 1993, 240). Armstrong seems prepared to bite this bullet, holding that it "could even be that the statement of, say, Newton's first law as an iron law, would have to be of infinite length" (Armstrong, 1983, 149). "Iron laws" is his term for exceptionless laws, while he calls cp laws "oaken": "Unlike iron laws, oaken laws do not hold no matter what. They hold only in the absence of interfering factors" (ibid., 106).
} 
may consider making the amendment "unless the bar is hammered inward at one end" (Lange, 1993, 233). But, this amendment would be of dubious value, because it is both too weak and too strong to restore the truth of the law. Not only does it fail to exclude other defeaters, it also wrongly excludes ineffective cases of hammering. After all, "the bar may be hammered upon so softly and be on such a frictionless surface that the hammering produces translation rather than compression of the bar" (ibid., 235). Hence, simply forbidding hammering will not do. Both considerations indicate that specified clauses do not capture the intuitive sense of "ceteris paribus", and both corroborate the insight gained in the precedeing section: As a general remedy for the problem of exceptions, the strategy of specifying antecedents is hopeless. And in fact, serious science does not employ it.

If all other things are never equal, "strictly speaking no ceteris paribus law literally applies" (Kincaid, 1996, 64). Kincaid concludes that cp laws "are apparently false when other things are not equal" (ibid. 67). But this conclusion comes too quick, for reasoning from a law's inapplicability to its falsity is invalid. If we think of the clause as a part of the antecedent, a cp law is not ipso facto false should the cp clause not be fulfilled. Just like Lipton, Kincaid seems to assume that a cp law asserts that all things are equal. But, under the assumption that a cp clause is an additional if-clause, laws qualified with such a clause assert what always happens if everything else is equal. If the proviso is not fulfilled, the conditional is not false, but vacuously true. - But all of this holds only if we choose clause (2) instead of (1), and this I would not advise.

The remaining clauses can hardly be reckoned literal translations of the Latin phrase "ceteris paribus". Yet it has become customary to discuss them under that heading, since there is some functional equivalence to the "original" cp clause. Clause (3), "under normal conditions", prompts the question which conditions count as normal. There are two options here, a statistical notion of normality and a teleological one. The statistical reading amounts to treating the normality clause as a quantifier. In this case, a cp law would be "a crude statistical law: for the most part ..." (Cartwright, 1983, 47). But most authors agree that the notion of normality invoked in clause (3) is not statistical. ${ }^{30}$ The reason is obvious: The circumstances under which the consequent of an empirical law becomes exactly true may be rare. As for the counterin-

\footnotetext{
${ }^{30}$ Cf. Cartwright, 1983, 47; Pietroski and Rey, 1995, 84 f.; Silverberg, 1996, 216 f.; with the exception of Schurz, 2001a, who bases his statistical notion of "normic laws" on a generalized theory of evolution. Schurz confines his account, however, to the phenomenological "system laws" of self-regulatory systems, in contrast to the "laws of nature", as he calls the fundamental laws of physics which are not restricted to special entities.
} 
stances due to the imperfect realization of ideal conditions, the rareness of positive instances of the law is only natural, for the probability of ideal conditions (no friction, a perfect vacuum etc.) is zero. As Lipton puts it: "Many cp laws have no instances, and it cannot be the case that most Fs are G if none are" (Lipton, 1999, 159).

Hempel has made it clear why probabilistic construals and cp laws are tailored to cope with different kinds of counterinstances. It is tempting to raise the empirical adequacy of, say, the theory of magnetism by a probabilistic construal, i.e., by resorting to laws such as "Given that a metal bar is magnetic, the probability that iron filings will cling to it is $p_{2}$ ". Hempel dismisses this idea, vaguely suggested by Carnap, on the grounds that "surely, the theory of magnetism contains no sentences of this kind; it is a matter quite beyond the theory's scope to state how frequently air currents, further magnetic fields, or other factors will interfere with the effect in question" (Hempel, 1988, 25). Thinking otherwise is asking too much of scientific theories. Nobody knows which numerical value of probability to assign to catastrophic interferences, i.e. to the chance that one out of an indefinite number of potential interferences will occur. Hempel concludes that "a probabilistic construal cannot avoid the need for provisos" (ibid.).

If the notion of normality invoked is not statistical but teleological, we arrive at clause (4), "under ideal conditions", or "under optimal conditions". Variants of the teleological clause include "other things being right" (Cartwright, 1983, 45), "in favourable circumstances", and "if the relevant circumstances do not change". Such clauses raise the question: "Relevant to, or optimal for what?" One obvious answer is, "for the effect to occur". This seems to be the only answer which makes sense, but it incurs the charges of circularity and vacuity. The teleological reading is responsible for the bad reputation of cp clauses in the empiricist camp. ${ }^{31}$ In effect, teleological normality clauses are equivalent with clause (5), "provided nothing interferes". As long as no independent characterization of the interfering factor can be given, advocates of clause (5) will have to explain what distinguishes the generalization " $B \mathrm{~s}$ follow $A$ s provided nothing interferes" from the statement " $B$ s follow $A$ s unless they don't".

Since cp laws had better not be equivalent with logical truths, clauses (4) and (5) are often combined with completer accounts of cp laws.

\footnotetext{
${ }^{31}$ According to Popper, clauses that fix circumstances "will be the more interesting the more specific they are, and the more testable they render the original theory. I therefore suggest that ceteris paribus clauses should be avoided and, more especially, that they should not be imported into the discussion of the methodology of the natural sciences" (Popper, 1974, 1187).
} 
The proviso "unless something interferes" is regarded as an invitation to determine the disturbing factor, whereas, as Geach puts it, "a vacuous expectation can in no wise guide further research" (Geach, 1973, 102). Pietroski and Rey, whose aim it is to save cp laws from the charge of vacuity, call cp clauses "cheques written on the bank of independent theories" (Pietroski and Rey, 1995, 89). If the cheque can be cashed afterwards by giving an independent explanation of the disturbing factor, the cp law has proved non-vacuous.

I wonder whether the cheque is credited to the right account. The better thing to say, to my mind, is that in such cases the explanation gets saved from vacuity. The explanation of why the expected effect did not occur may somehow be prompted by the cp clause, but since the completing condition is not supplied by any information the clause contains, the connection is quite loose. This looseness is a general weakness of completer accounts. The proviso may stimulate the scientist's imagination, but it is simply not true that it "guides" further research, as Geach demands. The issue under discussion is whether lawful statements qualified with (5) are trivially or non-trivially true, and any rejoinder which changes the wording of the law will change the subject. Hence, completer accounts are not suited to refute the charge of vacuity. ${ }^{32}$

The most exciting reading is arguably (6), the so-called ceteris absentibus clause. Geoffrey Joseph, who introduced this term in 1980, gives the following explanation:

Whether other factors are equal, or constant, is irrelevant. ... What would make laws literally true is not a ceteris paribus clause, but rather a ceteris absentibus clause. Each of the laws would be true were it restated as: 'Were it the case that all other factors are absent, then, given certain initial conditions, certain resultant conditions would obtain.' (Joseph, $1980,777)^{33}$

Joseph eventually rejects ceteris absentibus laws, but before considering his reason for doing so, let us take a closer look at the semantics of "ceteris absentibus". What distinguishes (6) from (5) is, first, that

\footnotetext{
32Hausman, following Stalnaker's distinction between the meaning of a sentence and its content, which may vary in different contexts, suggests that "ceteris paribus clauses have one meaning - 'other things being equal,' which in different contexts picks out different propositions or properties" (Hausman, 1992, 134). His assumption that the context, or rather the speaker's "background understanding" (ibid.), determines what the cetera are in each case, has the price of turning the completer account of cp laws into a pragmatic view. The charge of triviality, however, is commonly regarded as concerning the semantics and/or the logical form of a law-statement. - Glymour, too, endorses the view that cp claims have a pragmatics which accounts for their (limited) testability (Glymour, 2002).

${ }^{33}$ Johansson (Johansson, 1980, 18) and Hempel (Hempel, 1988, 23 and 29) have taken the same line.
} 
the factors which must be absent can, in a way, be given an independent characterization. If the cetera in question are other forces, as both Joseph and Hempel suggest, then we are in possession of what we always looked for: a clause which is "made fully explicit in a finite form" (Earman and Roberts, 1999, 443). Remember the stock objection to the clause "in the absence of other relevant factors", viz. that it "does not assert any determinate relation at all, because it fails to specify which other factors count as relevant" (Lange, 1993, 235). If the excluded factors are other physical forces, this objection is invalidated, for while potential catastrophic interferences cannot be specified in advance, physics does possess a finite and exhaustive list of fundamental physical forces: strong interaction, weak interaction, electromagnetic force, and gravitation.

The second thing to note about the ceteris absentibus clause is that it states a counterfactual condition: "Were it the case that ...". The idea suggests itself of combining such a clause with the dispositional view of laws of nature - the view that laws say how a system would behave under certain circumstances, e.g. in isolation. We should bear in mind, however, that we were looking for $\mathrm{cp}$ clauses as a remedy for the regularity view of laws. It should be obvious that counterfactual clauses cannot play this role, for the simple reason that "a counterfactual uniformity is no uniformity at all" (Cartwright, 1995b, 313).

But, the idea of combining the ceteris absentibus clause with the dispositional account of laws deserves to be assessed on its own merits. It faces the following difficulty, brought out by Joseph. As far as we know there is no situation, in the universe we inhabit, where only one of the fundamental physical forces is present. Gravitation, for instance, is omnipresent, there is no shielding from it. Therefore, the ceteris absentibus clause is never satisfied, just like clause (2). Supporters of the dispositional view are not worried by this fact, since they hold that laws make hypothetical claims anyway. But the situation is more serious than they think. The ceteris absentibus clause does not only establish a counterfactual condition, it posits counterlegal worlds, i. e., worlds which are nomologically impossible. Joseph explains why:

[A]ny possible world, distinct from the actual world, that makes the indicative form of a given one of the laws true must be different from every possible world that makes the indicative form of any of the other laws true. This is because the worlds are defined as worlds in which the sole field present is the field mentioned in a given law. There is no possible world in which both $F_{1}$ and $F_{2}$ are each the only field present. ... In denying the existence of other fields, these worlds deny the existential presuppositions of the remaining laws. (Joseph, 1980, 778) 
This is a disastrous result, for the very idea of laws of nature describing counterlegal worlds is an absurdity. ${ }^{34}$ Joseph puts it more mildly, expressing his "strong preanalytic intuition that an analysis of the truth conditions for scientific laws must make it possible for all of them to hold in this (actual) world" (ibid., $778 \mathrm{f}$.) To be sure, the problem is not just that the truth conditions of each law depend on those of other laws. Such holism could be true, after all. The deep problem is that the world is not given a chance to make two ceteris absentibus laws true at the same time.

Earman and Roberts suggest that the need for provisos "stops at the level of fundamental physics" (Earman and Roberts, 1999, 472). The truth is that it is interference all the way down, because it is interaction of forces all the way down. If physicists see no need to add provisos, but leave their laws as they are, this is because they are concerned with force laws, rather than with regularity claims of the kind discussed here. The latter are still plagued with exceptions, since the ceteris absentibus clause does not remove disturbing factors by merely stipulating that they be absent. The situation might change if a unified field theory should be developed which reduces the four fundamental physical forces (or three, meanwhile) to one. In an ideally completed physics with a unified force law, the source of disturbances would eventually run dry. But even if this were to happen, it would still be a long way from a unified force law to succession laws describing local regularities.

The clauses (2) through (6) having major drawbacks, I conclude that the first reading, "other things being equal", is the most appropriate one. It captures the linguistic meaning of the Latin phrase, it does not demand the impossible, and it does not make vacuously true the sentences it qualifies. It is unspecified, which is desirable, since cp clauses should be distinguished from the device of specifying antecedents.

\footnotetext{
${ }^{34}$ Applying the ceteris absentibus clause to the case of interaction between gravitation and electrical charge, Pietroski and Rey ask: "[W]hat counterfactuals shall we consider here? Shall we say that had protons and electrons lacked charge, the force exerted between them would have been equal to $G m m^{\prime} / d^{2}$ ? This seems absurd, if even intelligible. ... We doubt that anyone has any idea of what would it be to be a proton or electron without charge, much less how such particles would behave" (Pietroski and Rey, 1995, 105). Joseph makes the same point, using a different example: "Consider a proton in a nucleus of an atom in your finger. What determines its trajectory? Were it not for the strong interaction that overcomes the mutual electromagnetic repulsion between protons, there would be no nucleus. If there were no electromagnetic interaction between protons and electrons, there would be no atom. And if there were no gravitational interaction between atom and earth, the proton would float away along with the rest of you" (Joseph, 1980, 777).
} 


\section{Other Things Being Equal - To What?}

In discussing some of the literature, I could not avoid speaking of cp laws. I would have preferred to speak of cp clauses only. The whole debate about the trivialization charge is based on the assumption that cp clauses are in fact suited to modify lawful statements. I would like to take a step back and challenge this assumption. It is far from obvious that combining a lawful statement with a cp clause yields an intelligible proposition. In the remainder of the paper, I shall frankly advocate the view that, though cp sentences have important roles to play, there are no such things as cp laws.

So, let us make a fresh start. Philosophers of science have too long been absorbed in asking which other things are supposed to be equal. To my mind, the more pressing question is: equal to what? This question is hardly ever raised. Stephen Schiffer addresses the issue when he labels "deceptive" a ceteris paribus sentence such as "If a person wants something, then, all other things being equal, she'll take steps to get it". The sentence, according to Schiffer, "looks as though it's expressing a determinate proposition, because it looks as though 'all other things' is referring to some contextually determinate things and 'equal' is expressing some determinate relation among them" (Schiffer, 1991, 2). It's the last part of the quote which deserves attention. Which "determinate relation" does the word "equal" express in alleged cp laws? Agreed that it's certain conditions, or circumstances, which are supposed to be equal, or unchanged, the question is still: equal to what?

In a singular conditional about a particular situation, the answer would be obvious. Take the counterfactual conditional, "If I had not thrown the stone, the window would not have broken", which invites the objection that this is only true other things being equal. Equal to what? Equal to the factual circumstances of the event described in the antecedent. I did throw the stone, and as the definite article indicates, I did so in a particular situation - in specific, albeit undescribed, circumstances. The stone hit the window and broke it. Still, the truth of the unqualified counterfactual may be questioned. There could have been, say, an earthquake, so that the window would have broken even without the stone. In that very situation, however, there was no earthquake. And this is what the clause "other things being equal" does here: It fixes the circumstances that actually obtained. The equality condition has an anchorage, as it were, and therefore the cp clause has a determinate content. The hedged counterfactual reads: "If $e$ had not occurred, 
and if everything else had been as it was when e actually occurred, ${ }^{35} f$ would not have occurred".

In this counterfactual, "equal" has the meaning of "unchanged". The clause demands that the further circumstances remain as they are in the actual situation. Incidentally, this temporal reading is the only one that Webster's Dictionary reports: English usage of "ceteris paribus" expresses the provision that "all other relevant things, factors or elements remain unaltered". 36

Now it might be objected that the counterfactual I cited is true simpliciter, i.e. without the cp clause. On almost every view of the semantic of counterfactuals, we are taken only to the nearest possible world in which the antecedent holds, and this world does not contain earthquakes or other catastrophic interferences.

I agree that the nearest possible world in which the stone is not thrown does not contain an earthquake, but simply an unbroken window. But why is this so? The plain answer is that we do not have to consider earthquakes because in the situation at hand, none was in the offing. When reasoning counterfactually about particular situations, we do not brood over standards of comparative overall similarity, rather we simply refer to the facts that actually obtained up to the moment described in the antecedent. This direct reference to a singular, actual situation can be brought into the open by using demonstratives: this stone, that window. This is precisely what Goodman, in his early discussion of counterfactuals, did. One of his examples read: "If that match had been scratched, it would have lighted". ${ }^{37}$ It is only because a particular match in particular circumstances is referred to that we accept the counterfactual as true, for in general, scratching is not sufficient for the lighting of matches. But in the case at hand, the match was dry enough, the atmosphere did contain oxygen, etc. These circumstances do not get described, but they obtained, and the demonstrative reference exploits their determinacy. Though Goodman does not lay emphasis on the fact that his examples contain demonstratives, this fact strikes me as essential. Goodman does not supplement his conditional with a cp clause, but we may say that

\footnotetext{
35 More precisely "when" means "up to the occurrence of $e$ ", for the cp clause must leave room for the immediate consequences, causal and logical, of $e$ 's nonoccurrence. In other words, the nearest possible world is one which departs from the actual world just at the moment of $e$ 's occurrence. I am in agreement with Lewis here: "To get rid of an actual event $e$ with the least over-all departure from actuality, it will normally be the best not to diverge at all from the actual course of events until just before the time of $e$ " (Lewis, 1986, 171).

${ }^{36}$ Webster's Ninth New Collegiate Dictionary, Springfield, Mass. 1983.

${ }^{37}$ The definite articles I used in my example may be looked upon as "degenerate demonstrative singular terms" (Quine, 1960, 102), taking up Russell's observation that "the, when it is strictly used, involves uniqueness".
} 
in such conditionals, the demonstrative reference works as a substitute for the cp clause, or as an implicit cp clause. ${ }^{38}$ The hearer understands that in the given situation the requisite conditions obtained, so that explicit conditioning upon certain circumstances becomes redundant, just as Goodman suggests. The demonstrative reference ties the context of evaluation to the context of utterance.

To be sure, $\mathrm{cp}$ conditionals need not be in the subjunctive mood. "If I pour this acid into the test-tube, the litmus tincture will turn red, other things being equal." In this indicative, future-directed conditional, the proviso plays the same role as in the counterfactuals above. As long as the antecedent describes a singular situation, the clause can be spelled out as "and if everything else remains unaltered". 39 And if someone accepts the conditional as true even without such a clause, he does so because he understands the constancy assumption as a built-in feature of the conditional.

But we must not lose sight of our original concern. We were out for cp laws. Thus, a hedged universal statement is called for. The analogous formulation would have to be: "Whenever $F x$, then, other things remaining unchanged, $G x$ ". Such conditionals sound familiar, but they invite the hard question: unchanged with respect to what?! No circumstances that could remain unchanged or equal are mentioned in a universally quantified conditional, and none could be mentioned, for making a demonstrative reference to an individual situation is not admissible in a genuinely universal statement. Hence, the cp clause has no anchorage here. It is floating free. If spelled out as a constancy requirement, the cp clause is a foreign element in lawlike sentences, syntactically unfit to qualify universal propositions.

So, under the assumptions that the logical form of a law is a universally quantified conditional, and that "ceteris paribus" is to be translated as "other things being equal", there are no such things as ceteris paribus laws, for reasons of logical form. Cp clauses have singular propositions as

\footnotetext{
${ }^{38}$ Goodman says: "Notice especially that our assertion of the counterfactual [sc. "If that match had been scratched, it would have lighted"] is not conditioned upon these circumstances obtaining. We do not assert that the counterfactual is true if the circumstances obtain; rather, in asserting the counterfactual we commit ourselves to the actual truth of the statements describing the requisite relevant conditions" (Goodman, 1954, 8).

${ }^{39}$ Eventually, the word "else" (or "other"), hitherto mysterious, makes sense. Everything remains unchanged except the change described in the conditional. The objection to clause (2), that all things are never equal since history does not repeat itself, loses its point now. The cases compared are no longer two instantiations of a law, but two singular events or states, one described in the antecedent and one described in the consequent, and the alteration exempted from the constancy requirement is just the change between them. Clause (2) gets vindicated, eventually.
} 
their habitat, not general ones. A cp clause spelled out as a constancy requirement makes a demonstrative reference to particular circumstances, while such circumstances cannot be referred to in law-statements. Constancy requirements have their anchorage outside of law-statements, and it's only because of their indexical nature that they have a determinate content at all. ${ }^{40}$

Why has this fact persistently evaded our notice? One reason could be that some cp conditionals are so closely related to corresponding law-statements. Cp clauses need a reference situation, and when formulating an alleged cp law, there is a natural candidate for that reference situation, viz. the experimental situation which gives reason to the formulation of the law, or which confirms it.

The case of experimentation shows quite clearly what the original habitat of cp clauses is, and which role they play there. Bringing about $f$ by doing $e$ worked once, so the experimenter frames a hypothetical law. Experiments are supposed to be repeatable, and in trying to do it again, the scientist must keep constant, or reproduce, the circumstances which obtained the first time. Sometimes he fails, and some of his failings he explains by the conjecture that other things were not equal. In testing quantitative laws, perfect match between the measured result and the predicted result is hard to achieve. The most the scientist can expect is that the gap will progressively decrease the more exactly he reproduces the original circumstances. Galilean idealization has a crucial role to play here. All of this is familiar. The important thing to note is that the phrase "the circumstances which obtained the first time" makes no contact in lawlike sentences.

The upshot is that cp clauses have no business in laws, but only in singular propositions. Although this fact has mostly gone unnoticed, there are a few hints of it in the literature. As quoted above, Schiffer admits cp sentences, but not cp laws. Cartwright comes close to the negative part of my conclusion when she distinguishes "between the descriptions that belong inside a law statement and those that should remain outside as a condition for the regularity described in the law to obtain" (Cartwright, 1995a, 278-9; see also Earman, Roberts and

\footnotetext{
${ }^{40}$ Still, there seems to be one more use of "other things being equal", where the objection that the equality requirement makes no contact ceases to apply. Consider "Other things being equal, if one boat is newer than another it will be more expensive." Here, the cetera are other factors which could affect the prices of boats. This "comparative interpretation" of the cp clause (Morreau, 1999, 171) requires that the two compared items are both mentioned, so that the question "equal to what?" has an obvious answer: equal in both cases. But, no cp laws are likely to emerge from such examples. In effect, the sentence doesn't say more than that for boats age is a price-affecting factor.
} 
Smith, 2002, 287). The more specific insight into the indexical nature of cp clauses is foreshadowed in a remark of Quine's ${ }^{41}$ and in Morreau's "pragmatic" paraphrase of the cp clause. ${ }^{42}$ None of them, however, draws conclusions for the notion of a cp law.

Generally, the logical difficulty of combining a general statement with a constancy clause is being overlooked. The capricious way in which the cp clause is inserted into law-statements by various authors is telling. Every conceivable placement can be found: Kincaid, Pietroski and Rey let the law-statement begin with the cp clause, Kurtzman writes the clause between the quantifier and the antecedent, Silverberg and Schiffer behind the sentential connective, Fodor sometimes before the law, sometimes at the end, Cartwright mostly into the antecedent, and for Schurz the clause is part of the connective, which he takes as a "normic" conditional operator. One should think that it makes a difference whether a constituent of a law-statement is part of the antecedent or of the consequent, or whether it is quantified over or not, or whether it is itself a quantifier. Once we acknowledge that the cp clause is not a logical constituent of the law, the diversity of positionings becomes less amazing. On most of the readings discussed above, the cp clause has the logical form of an additional if-clause. Syntactically, such a clause may in principle be placed before, within or behind the law-statement, the effect always being that it sets an additional condition that limits the number of cases covered by the law. But on closer examination, the clause can only play that role if the constancy condition has an anchorage somewhere: equal to what? The only intelligible answer I found goes: "equal to the factual circumstances of the event mentioned in the antecedent". This answer works only with singular conditionals, not with general ones. In singular conditionals, the clause has a determinate content, insofar as it taps the determinacy of the situation which actually obtained. It is worth noting that such singular conditionals play an important role in counterfactual analyses of event causation, though their singularist character has not always been recognized.

We arrive at counterfactuals of the sort "If $e$ had not happened, and if everything else had been as it was when $e$ actually happened, $f$ would not have happened". These conditionals are perfectly intelligible, but they

\footnotetext{
${ }^{41}$ Quine observes that the "clues to the scope of 'ceteris paribus'... are afforded by the context or other special circumstances of the particular utterance" (Quine, 1960, 225).

${ }^{42} \mathrm{Cp}$ clauses, says Morreau, "can be used to hedge claims against the possibility of changed circumstances" (Morreau, 1999, 165). His "pragmatic" paraphrase "ties the interpretation of the modifier to some context of evaluation; for a thing, factor or element to 'remain unaltered', it must remain as it is there" (ibid., 166). An observation of Hausman's (see above, fn. 32) also points into that direction.
} 
cannot be turned into laws. A law cannot be combined with an indexical constancy clause, since the clause has its required relatum outside the law, and the resulting hybrid statement, half-singular and half-universal, would be hard to make sense of. Given the assumptions I made, there are no such things as cp laws.

By the same token, cp clauses cannot be used to restore the truth of succession laws in the face of exceptions. Thus, they cannot be used to support the cause-law thesis. But as I just pointed out, they can do something better for the theory of causality. Cp clauses retain their function when combined with singular counterfactuals, and they actually do a good job in the counterfactual theory of event causation. ${ }^{43}$ The truth conditions of causal counterfactuals cannot be given, of course, by corresponding laws, since strict causal laws are nowhere to be found, while true causal counterfactuals abound. Not being supported by strict laws of succession, causal counterfactuals have to stand on their own feet. But that's a different matter.

It might be objected that this sketch of a solution works only for the first of the six readings of "ceteris paribus" which I distinguished. This is true, but I must remind the reader that I had rejected the other paraphrases for independent reasons.

Moreover, I had narrowed down my attention to empirical laws of succession. So in a way, I agree with the view that "ceteris paribus stops at the level of fundamental physics" (Earman and Roberts, 1999, 472). Exceptions being counterinstances, the notion of exception has no application to laws which do not purport to describe what actually happens. Interpreted in a certain way, force laws need no hedging. They can remain true even if in the real world forces always interact.

Earman, Roberts and Smith have argued that since cp claims are "open-ended" and have no determinate content, they cannot be laws. I agree with their conclusion that there are no cp laws, but not with their view of cp clauses. In the counterfactuals at hand, cp clauses are not open-ended. They do have a determinate content and determinate truth conditions. But since this content is indexical, cp clauses are unfit for being combined with laws. The linguistic meaning of "ceteris paribus" is "other things being equal", while the clause gets its context-dependent propositional content by exploiting a particular context of utterance.

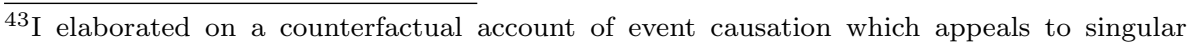
counterfactuals with indexical cp clauses in my (Keil, 2000, 261-279 and 431-457).
} 


\section{References}

Armstrong, D. (1983). What is a Law of Nature? Cambridge.

Bhaskar, R. (1978). A Realist Theory of Science. Hassocks, Sussex, 2 edition.

Cartwright, N. (1983). How the Law of Physics Lie. Oxford.

Cartwright, N. (1989). Nature's Capacities and their Measurement. Oxford.

Cartwright, N. (1992). Aristotelian natures and the modern experimental method. In Earman, J., editor, Inference, Explanation and Other Philosophical Frustrations, pages 44-71, Berkeley.

Cartwright, N. (1995a). Ceteris paribus laws and socio-economic machines. The Monist, 78:276-294.

Cartwright, N. (1995b). How laws relate what happens: Against a regularity account. In Stachowiak, H., editor, Pragmatik. Handbuch pragmatischen Denkens, volume V, pages 305-314, Hamburg.

Cartwright, N. (1999). The Dappled World. A Study of the Boundaries of Science. Cambridge.

Cummins, R. (1983). The Nature of Psychological Explanation. Cambridge, Mass.

Davidson, D. (1980a). Essays on Actions and Events, chapter Mental Events, pages 207-225. Oxford.

Davidson, D. (1980b). Essays on Actions and Events, chapter Actions, Reasons and Causes, pages 3-19. Oxford.

Davidson, D. (1993). Replies. In Stoecker, R., editor, Reflecting Davidson, Berlin/New York.

Davidson, D. (1995). Laws and cause. Dialectica, 49:263-279.

Dretske, F. (1977). Laws of nature. Philosophy of Science, 44:248-268.

Ducasse, C. J. (1968). On the analysis of causality [1957]. In his Truth, Knowledge and Causation, pages 15-20. London/New York.

Earman, J. and Roberts, J. (1999). Ceteris paribus, there is no problem of provisos. Synthese, 118:439-478.

Earman, J., Glymour, C. and Mitchell, S. (2002). Editorial. Erkenntnis, $57: 277-280$.

Earman, J., Roberts, J. and Smith, S. (2002). Ceteris paribus lost. Erkenntnis, 57:281-301.

Fodor, J. A. (1991). You can fool some of the people all of the time, everything else being equal. Hedged laws and psychological explanations. Mind, 100:19-33.

Geach, P. T. (1973). Aquinas. In: G. E. M. Anscombe and P. T. Geach Three Philosophers. Oxford, pages 64-126. 
Giere, R. N. (1988). Laws, theories, and generalizations. In Grünbaum, A. and Salmon, W., editors, The Limitations of Deductivism, pages 37-46, Berkeley/London.

Glymour, C. (2002). A semantics and methodology for ceteris paribus hypotheses. Erkenntnis, 57:395-405.

Goodman, N. (1954). Fact, Fiction, and Forecast. London.

Guarini, M. (2000). Horgan and Tienson on ceteris paribus laws. Philosophy of Science, 67:301-315.

Hausman, D. M. (1992). The Inexact and Separate Science of Economics. Cambridge.

Hempel, C. G. (1988). Provisos: A problem concerning the inferential function of scientific theories. In Grünbaum, A. and Salmon, W. C., editors, The Limitations of Deductivism, pp. 19-36, Berkeley/London.

Horgan, T. and Tienson, J. (1996). Connectionism and the Philosophy of Psychology. Cambridge, Mass./London.

Hüttemann, A. (1998). Laws and dispositions. Philosophy of Science, $65: 121-135$.

Johansson, I. (1980). Ceteris paribus clauses, closure clauses and falsifiability. Journal for General Philosophy of Science, 11:16-22.

Joseph, G. (1980). The many sciences and the one world. Journal of Philosophy, 77:773-791.

Keil, G. (2000). Handeln und Verursachen. Frankfurt am Main.

Kincaid, H. (1996). Philosophical Foundations of the Social Sciences. Cambridge.

Klee, R. (1992). Anomalous monism, ceteris paribus and psychological explanation. British Journal for the Philosophy of Science, 43:389403.

Kurtzman, D. R. (1973). Ceteris paribus clauses: Their illumination and elimination. American Philosophical Quarterly, 10:35-42.

Lakatos, I. (1978). Philosophical Papers, volume I, chapter Fallibilism and the Methodology of Scientific Research Programmes, pages 8101. Cambridge.

Lange, M. (1993). Natural laws and the problem of provisos. Erkenntnis, $38: 133-148$.

Lewis, D. (1986). Philosophical Papers. Oxford.

Lipton, P. (1999). All else being equal. Philosophy, 74:155-168.

Mackie, J. L. (1980). The Cement of the Universe. A Study of Causation [1974]. Oxford, 2 edition.

Mill, J. S. (1973). A System of Logic, Ratiocinative and Inductive [1843]. Toronto, 4 edition. (Collected Works, Vol. VII/VIII).

Morreau, M. (1999). Other things being equal. Philosophical Studies, 96:163-182. 
Nagel, E. (1961). The Structure of Science. London.

Persky, J. (1990). Ceteris paribus. Journal of Economic Perspectives, 4:187-193.

Pietroski, P. and Rey, G. (1995). When other thing's aren't equal: Saving ceteris paribus laws from vacuity. British Journal for the Philosophy of Science, 46:81-110.

Popper, K. R. (1974). Replies to my critics. In Schilpp, P. A., editor, The Philosophy of Karl Popper, Bk. II, pages 961-1197, La Salle, Ill.

Quine, W. V. O. (1960). Word and Object. Cambridge, Mass.

Robbins, L. (1984). The nature and significance of economic science [1935]. In Hausman, D. M., editor, The Philosophy of Economics, pages $83-110$, Cambridge.

Russell, B. (1948). Human Knowledge. Its Scope and Limits. New York.

Russell, B. (1986). On the notion of cause [1912]. In his Mysticism and Logic, London.

Schiffer, S. (1991). Ceteris paribus laws. Mind, 100:1-17.

Schurz, G. (2001a). Pietroski and Rey on ceteris paribus laws. British Journal for the Philosophy of Science, 52:359-370.

Schurz, G. (2001b). What is 'normal'? An evolution-theoretic foundation of normic laws and their relation to statistical normality. Philosophy of Science, 68:476-497.

Scriven, M. (1959). Truisms as the grounds for historical explanations. In Gardiner, P., editor, Theories of History, pages 443-475, New York/ London.

Scriven, M. (1961). The key property of physical laws - inaccuracy. In Feigl, H. and Maxwell, G., editors, Current Issues in the Philosophy of Science, pages 91-101, New York.

Silverberg, A. (1996). Psychological laws and non-monotonic logic. Erkenntnis, 44:199-224.

Smith, S. (2002). Violated laws, ceteris paribus clauses, and capacities. Synthese, 130:235-264.

Steiner, M. (1986). Events and causality. Journal of Philosophy, 83:249264.

Swartz, N. (1985). The Concept of Physical Law. Cambridge.

Tye, M. (1992). Naturalism and the mental. Mind, 101:421-441.

van Fraassen, B. C. (1989). Laws and Symmetry. Oxford.

Warfield, T. (1993). Folk psychological ceteris paribus laws? Philosophical Studies, 71:99-112.

Woodward, J. (2000). Explanation and invariance in the special sciences. British Journal for the Philosophy of Science, 51:197-254. 